\title{
Studies on the Incrimination Rates of two Minor Vectors - Anopheles gambiae and Anopheles funestus Complexes in the Transmission of Bancroftian Filariasis in Makurdi, North Central Nigeria
}

\author{
M. M. Manyi1 , A. A. Dechi², A. I. Kwaghbo³
}

${ }^{1}$ Applied Entomology and Parasitology Unit, Department of Biological Sciences, Federal University of Agriculture P M B 2373, Makurdi, Benue State, Nigeria

${ }^{2}$ Department of Biology, College of Education P M B 2008, Katsina- Ala, Benue State, Nigeria

${ }^{3}$ Department of Biology, College of Advanced and Professional Studies, Benue State, Nigeria

\begin{abstract}
Studies on the roles of Anopheles gambiae and Anopheles funestus complexes in the transmission of Wuchereria bancrofti in Makurdi, Nigeria across four localities: High-level, Wurukum, North- bank and Wadata were undertaken from July, 2011 to June, 2012. 1,681 adult female mosquitoes were identified and dissected with the aid of standard keys and procedures to determine their incrimination rates with microfilariae of Wuchereria bancrofti. 1,040 (61.87\%) of these were Anopheles gambiae sensu lato while 641 (38.13\%) were Anopheles funestus. The results showed a significant difference $(P<0.05)$ between the mosquito species and their abundance. The overall microfilarial incrimination rate was 5.77\% (97/1,681); Anopheles gambiae s.1. was more incriminated (3.57\%) than Anopheles funestus $(2.20 \%)$. The incrimination rates differed significantly $(P<0.05)$ between the two mosquito species surveyed. ANOVA also showed significant variations $(\mathrm{P}<0.05)$ in the microfilarial incrimination rates across the localities and seasons: North-bank locality had the highest microfilarial incrimination rate of $17.23 \%$ while mosquitoes from High level, Wurukum and Wadata localities had similar incrimination rates of $3.94 \%, 3.93 \%$ and $3.79 \%$ respectively. These rates were higher during the dry season than the wet period. The results revealed potential risk of lymphatic filariasis transmission among residents of Makurdi, since the two Anopheles vectors effectively harboured microfilariae of Wuchereria bancrofti in their salivary glands. However, determination of microfilarial infection rates in human population is recommended in the study area. The results of the present investigation may provide entomological baseline data required for both present and future implementation of vector/disease control interventions in Makurdi
\end{abstract}

Keywords: Anopheles funestus, Anopheles gambiae, Incrimination, microfilarial infection, Makurdi, Nigeria.

\section{Introduction}

Mosquitoes belonging to the genera Anopheles have been reported to be vectors for pathogens of major diseases such as malaria and filariasis (Dandalo, 2007). The World Health Organisation (WHO, 2002) reported that even when mosquito bites are not infective, they may cause great nuisance, making areas originally suitable for human and animal operations quite uninhabitable. Vector borne diseases in general and mosquito borne diseases in particular, are worldwide and they exert enormous burden on the continent of Africa (Coetzee, 2000).

Lymphatic filariasis is one of the most common mosquito-borne parasitic diseases worldwide (Manguin et al., 2010). Filariasis is an infection of the human lymphatic system caused by filarial parasites that are vectored by mosquitoes (Manguin et al., 2010). It has been reported that 1.3 billion people are at risk of the disease worldwide and the

This article is published under the terms of the Creative Commons Attribution License 4.0

Author(s) retain the copyright of this article. Publication rights with Alkhaer Publications.

Published at: http://www.ijsciences.com/pub/issue/2016-05/

DOI: 10.18483/ijSci.763; Online ISSN: 2305-3925; Print ISSN: 2410-4477 
disease is classified into two groups, Bancroftian (Wuchereria bancrofti) and Malayan (Brugia malayi and B. timori) (WHO, 2010). Although, designated by the WHO as the world's second leading cause of permanent and long-term disability, filariasis is "potentially eradicable" through drug therapy and mosquito vector control (WHO, 2010).

It has been reported that Wuchereria bancrofti, the nematode responsible for the disease in Africa, is transmitted by Culex quinquefasciatus in urban and semi-urban areas where increased pollution of freshwater bodies and the introduction of pit latrines favour the breeding of the mosquito (Badaki, 2010; Service, 2012). However, in West Africa, Anopheles gambiae complex and Anopheles funestus are the major transmitters of Wuchereria bancrofti infections (Coetzee et al., 2000).

Transmission of bancroftian infection occurs mainly during wet season when mosquito vectors are most numerous, thus delineating defined seasons when transmission is high and low (Badaki, 2010). In Nigeria, the epidemiology of Lymphatic filariasis is complicated as a result of the diversity of environmental conditions of the different regions (Anosike et al., 2003). Only bancroftian filariasis is reported to be endemic in Nigeria, especially for rural communities in the lower Cross River Basin (Udoidung et al., 2008; Okon et al., 2010); for Ezza in Ebonyi State (Anosike et al., 2005); for Igwu basin of Rivers State and parts of the Niger Delta (Udonsi, 1988; Agi and Ebenezer, 2009) as well as parts of Central Nigeria, particularly rural communities in Plateau, Nassarawa and Benue States (Eigege et al., 2003).

Mosquito vectors which breed and transmit bancroftian filariasis in Nigeria are aided by human activities, brought about by urbanization and overcrowding as well as industrialization which together create abundant breeding sites (Nwoke et al., 2010). The availability and proximity of human settlements to these numerous breeding sites of the vectors play an important role in the disease transmission and intensity in both rural and urban settings (Anosike et al., 2003; Nwoke, 2010).

Nigeria has been reported to be second highest with lymphatic filariasis globally (FMOH, 2009). This led to the establishment of the National Lymphatic Filariasis Elimination programme (NLFEP) in 1997 with the mandate of eliminating Lymphatic Filariasis (LF) as a Public Health problem. In 2007, the NLFEP was merged with the National Onchocerciasis Control Programme (NOCP) so as to integrate implementation of mass drug administration (MDA) in localities that were co-endemic for both LF and Onchocerciasis (Badaki, 2010; FMOH,
2009). However, the NLFEP has not yet been able to complete the mapping of the disease up till date. MDA is therefore, yet to commence in most of the states likely to be endemic (Badaki, 2010). Reports from the Federal Ministry of Health (FMOH, 2009) have shown that MDA has been implemented in only five states (Plateau, Nassarawa, Ekiti, Ondo and Osun).

The role of Anopheles species in the transmission of lymphatic filariasis has been underestimated while much attention has been focused on the principal vector of the disease- Culex quinquefasciatus. Therefore, the need to ascertain microfilarial incrimination rates of Anopheles species in other parts of the country like Benue State is not negotiable for the commencement of MDA. The present study determined the roles of the principal Anopheles vectors: Anopheles gambiae complex and Anopheles funestus, in the transmission of bancroftian filariasis in Makurdi, North Central Nigeria.

\section{Materials and Methods \\ Study Area}

The present study was carried out from July, 2011 to June, 2012 in Makurdi across wet and dry season months. Makurdi is the capital of Benue State situated in the middle belt region of Nigeria (Federal Republic of Nigeria, Official Gazzette, 2007). It is intersected by river Benue- a major source of water that branch into networks of streams, standing pools, over filled and blocked drainages (Omudu and Ochoga, 2011). Over-grown bushes and fields are prominent in Makurdi, even around residential houses and offices. These provide abundant breeding sites for mosquitoes throughout the wet and dry seasons. The temperature in the region is characteristically high, ranging from $30^{\circ} \mathrm{C}-39^{\circ} \mathrm{C}$. This high temperature is perceived to speed up the development and hatching of mosquitoes' eggs and this may have an impact on transmission of vector diseases in the area. Makurdi is located between longitude $8^{\circ} 35^{\prime} \mathrm{E}$ and $8^{\circ} 41^{\prime} \mathrm{E}$ and latitude $7^{\circ} 45^{\prime} \mathrm{N}$ and $9^{\circ} 52^{\prime} \mathrm{N}$. Other geographical and regional indices of the area have been presented by (Nigerian Metrological Agency, 2011; Udo, 1981; Nyagba, 1995).

\section{Collection of Mosquito Samples}

Verbal informed consent was obtained from the heads of the randomly selected households before their houses were accessed for mosquito collection in all the study localities. The mosquito samples were collected using standard procedures as provided by (WHO, 1975). Sampling units were randomly selected from four localities and the mosquito samples were collected with the assistance of "fly boys" who were trained and recruited from the various study localities where they were well known 
by the residents of the localities sampled.

Mosquito samples were collected between the hours of dawn and dusk, specifically from 0600-0900 hours at dawn and 1800-2100 hours at dusk from living rooms in the study localities.

The timing of sample collection was based on previous reports that most mosquitoes enter houses to feed early at night and struggle to go out in the early hours of the day to rest outdoors (Service, 2012; Laumann, 2010).

The mosquitoes were collected from dark corners, walls, ceilings, clothing and other objects inside living rooms with the aid of mouth-aspirators, mosquito sweep nets, Pyrethrum Spray Catches (PSC) and window trap method where applicable (Dandalo, 2007).

The collected mosquito specimens were kept in holding tubes, inside cooling boxes, and carried to the laboratory on the same day or the following day for characterization, identification, dissection and examination using the methods of WHO (1975); Ungureanu (1972); Goodman et al. (2003); Aigbodion and Nnoka (2008); Abeyasingha et al. (2009). Those mosquito samples that could not be processed on the same day were refrigerated and processed the next day following the methods of Ungureanu (1972).

The mosquito population for the present survey was only drawn from indoor-resting mosquitoes, which were expected to be only females but some male mosquitoes were also caught along with the females. Male mosquitoes were therefore, distinguished from the females using key morphological features as described by Service (2012).

\section{Identification of Mosquito Samples}

Dissecting microscope was used for detailed observation and identification of the mosquitoes with particular reference to the head, thorax, wings and hind-legs according to Gillies and Coetzee (1987). Morphological characteristics such as length of maxillary palps, wing spots, leg shape, mouthparts and abdominal end model as presented by Service (2012), Oguoma et al. (2010) were used to identify Anopheles gambiae complex and Anopheles funestus mosquitoes. Culex and other mosquito species that were collected alongside the two Anopheles species in question were discarded. Observations of the morphological features were made at 40x magnification of the dissecting microscope.

\section{Preparation of Mosquitoes for Dissection}

Live blood fed mosquitoes were killed with chloroform but unfed mosquitoes were collected in a test tube and while at the bottom, the end of the tube was raped sharply against the palm of the hand to stun the mosquitoes according to the WHO standard (Manguin et al., 2010). After immobilization, each mosquito was placed on a slide and held by one wing while the legs were being removed one at a time and after wards, the other wing was pulled off. The mosquito was then placed on a fresh dry slide and arranged in a more suitable position for dissection of the abdominal region and salivary glands as described by (WHO, 1975) and as adopted by Abeyasingha et al. (2009).

\section{Dissection of the Salivary Glands for Determination of Incrimination Rates}

This was done using the procedure described by Abeyasingha et al. (2009). The intention was to incriminate the two major Anopheles vectors and establish their microfilarial infection rates for both Anopheles species collected.

The anterior part of the mosquito to be dissected was placed on a slide with the head pointing to the right hand side and a drop of physiological saline was added to keep the specimen fresh. Meanwhile, the left dissecting needle was placed gently on the thorax, just below the region where the glands lie. The right needle was also placed at the same point but pulled towards the right direction to bring out the head with the salivary glands attached. Some salivary glands however, did not come out with the head of the mosquito but these were located by carefully teasing the lower part of the thorax and examining carefully.

The glands were detached from the head and then placed on another microscope slide with a little drop of saline and covered with a cover slip and a gentle pressure was exerted on the cover slip to rupture the gland cells. The thoracic muscles were then teased carefully in a saline solution to look for microfilariae. If the salivary glands contained microfilariae, these were seen to emerge from the glands as minute spindle-shaped structures of $\approx 15 \mu$ in length.

The microfilariae dissected out of the mosquitoes for this study all had nuclei which did not reach their tails, the tails tapered evenly and they also had sheaths. These features were therefore, convincing enough to classify them as those of Wuchereria bancrofti as described by Chandler and Read (1969). Wuchereria bancrofti larval stages $\left(\mathrm{L}_{1}, \mathrm{~L}_{2}\right.$ and $\left.\mathrm{L}_{3}\right)$ were also sought for during dissection from the three parts of the female mosquitoes (abdomen, thorax and head respectively) using their morphological features after they were stained with Giemsa's stain as described by Chandler and Read (1969); Kasili et al. 
Studies on the Incrimination Rates of two Minor Vectors - Anopheles gambiae and Anopheles funestus Complexes in the Transmission of Bancroftian Filariasis in Makurdi, North Central Nigeria

(2009). Incrimination of the Anopheles species was calculated in terms of microfilarial infection rate using the formula adopted by Kasili et al. (2009) as follows:

$$
\text { Infection Rate }=\frac{\text { Number of Mosquitoes carrying } L_{1}+L_{2}+L_{3}}{\text { Number of Mosquitoes dissected }} \times 100
$$

\section{Data Analysis}

The Predictive Analytical Software (PASW) Version 18 was used in running Chi-square $\left(\chi^{2}\right) \quad$ statistic and one-way Analysis of Variance (ANOVA) on the data collected. Significant levels were measured at 95\% confidence level with significant differences considered at $\mathrm{P}>0.05$.

\section{Results}

The results of this study are depicted in Tables 1,2 \& 3. Of the 1,681 Anopheles mosquitoes collected and dissected, $97(5.77 \%)$ of them were incriminated with microfilariae of Wuchereria bancrofti. In terms of study localities and mosquito abundance, the highest number of mosquitoes $554(32.96 \%)$ were collected from Wadata locality while the lowest number 238 (14.16\%) were collected from North-bank locality. North-bank had the highest microfilarial incrimination rate of $17.23 \%$, followed by High-level $(3.94 \%)$, then Wurukum locality $3.93 \%$ while Wadata locality had the least incrimination rate of $3.79 \%$ respectively (Figure 2 ). These differences in microfilarial incrimination rates across the localities were significantly different $(P<0.05)$

Comparing the microfilarial incrimination rates with respect to species of Anopheles mosquitoes collected in the study area, Anopheles gambiae s.l. had the highest incrimination rate of $3.57 \%$ while Anopheles funestus had the lowest microfilarial incrimination rate of $2.20 \%$ respectively. However, Anopheles funestus had the highest incrimination rate of $44.93 \%$ as against the $31.76 \%$ for Anopheles gambiae s.l. during the dry season (Table 3). Statistically, there

Table 1: Microfilarial Incrimination Rates of Anopheles Mosquitoes Dissected from four Localities in Makurdi

\begin{tabular}{lllcl}
\hline & & \multicolumn{3}{l}{ Species of Mosquitoes/Incrimination Rates (\%) } \\
\cline { 3 - 5 } Study Locality & $\begin{array}{l}\text { No of } \\
\text { Mosquitoes } \\
\text { dissected (\%) }\end{array}$ & Anopheles gambiae & Anopheles funestus & Total Incrimination (\%) \\
& $355(21.12)$ & $2 / 241(0.83)$ & $12 / 114(10.53)$ & $14(3.94)$ \\
High Level & $534(31.77)$ & $12 / 252(4.76)$ & $9 / 282(3.19)$ & $21(3.93)$ \\
Wurukum & $238(14.16)$ & $32 / 121(26.45)$ & $9 / 117(7.69)$ & $41(17.23)$ \\
Worth-bank & $554(32.96)$ & $14 / 426(3.29)$ & $7 / 128(5.47)$ & $21(3.79)$ \\
TOdata & $\mathbf{1 , 6 8 1}(\mathbf{1 0 0})$ & $\mathbf{6 0}(\mathbf{3 . 5 7})$ & $\mathbf{3 7 ( 2 . 2 0 )}$ & $\mathbf{9 7 ( 5 . 7 7 )}$ \\
\hline
\end{tabular}

was a significant difference $(P<0.05)$ between the microfilarial incrimination rates and the mosquito species (Table 1, $2 \& 3$ ).

Table 2 presents the overall monthly abundance of Anopheles species and microfilarial incrimination rates in the Anopheles vector population in the study area. In terms of abundance, Anopheles gambiae sl was more abundant 1,040 (61.87\%) than Anopheles funestus $641(38.13 \%)$. The highest number of mosquitoes $334(19.87 \%)$ were collected in August followed by September $261(15.53 \%)$ while the lowest mosquito population $16(0.95 \%)$ was recorded in December, 2011 followed by January, 2012, which had $30(1.78 \%)$ mosquitoes respectively. Anopheles gambiae sl was collected for all other study months except for July and September of 2011 as well as March of 2012. While Anopheles funestus was collected for all other months except for July and August, 2011. The results revealed a significant difference $(P<0.05)$ in the distribution of the vector species across the months of study. The highest microfilarial incrimination rate $(68.75 \%)$ was recorded in December, 2011 with similar such rates occurring in the other dry season months while the lowest rates were recorded in the wet season months with no single infection recorded in July, 2011. ANOVA showed significant differences $(P<0.05)$ in the microfilarial incrimination rates both with regard to the months/seasons during which the mosquito samples were collected and with respect to Anopheles species;

$\chi^{2}=18.387, \mathrm{df}=3, \mathrm{P}=0.001<0.05$.

Table 2: Monthly Microfilarial Incrimination Rates of Anopheles gambiae s.l. and Anopheles funestus in Makurdi 
Studies on the Incrimination Rates of two Minor Vectors - Anopheles gambiae and Anopheles funestus Complexes in the Transmission of Bancroftian Filariasis in Makurdi, North Central Nigeria

\begin{tabular}{lllll}
\hline Month of Study & $\begin{array}{l}\text { No } \\
\text { Mosquitoes } \\
\text { dissected (\%) }\end{array}$ & Anopheles gambiae & Anopheles funestus & Total Incrimination (\%) \\
\hline July, 2011 & $228(13.56)$ & $0 / 126(0.00)$ & $0 / 102(0.00)$ & $0 / 228(0.00)$ \\
August, 2011 & $334(19.87)$ & $1 / 109(0.92)$ & $0 / 109(0.00)$ & $1 / 334(0.29)$ \\
September, 2011 & $261(15.53)$ & $0 / 141(0.0)$ & $1 / 120(0.83)$ & $1 / 261(0.38)$ \\
October, 2011 & $84(4.99)$ & $9 / 53(16.98)$ & $5 / 31(16.13)$ & $14 / 84(16.67)$ \\
November, 2011 & $31(1.84)$ & $11 / 21(52.38)$ & $8 / 10(80.00)$ & $19 / 31(61.29)$ \\
December, 2011 & $16(0.95)$ & $7 / 10(70.00)$ & $4 / 6(66.67)$ & $20 / 30(66.67)$ \\
January, 2012 & $30(1.78)$ & $14 / 22(63.64)$ & $6 / 8(75.00)$ & $17 / 43(39.53)$ \\
February, 2012 & $43(2.56)$ & $15 / 29(51.72)$ & $2 / 14(14.29)$ & $5 / 97(5.15)$ \\
March, 2012 & $97(5.77)$ & $0 / 66(0.00)$ & $5 / 31(16.13)$ & $4 / 173(2.31)$ \\
April, 2012 & $173(10.29)$ & $1 / 111(0.90)$ & $3 / 62(4.84)$ & $3 / 195(1.54)$ \\
May, 2012 & $195(11.60)$ & $1 / 120(0.83)$ & $2 / 75(2.67)$ & $2 / 189(1.06)$ \\
June, 2012 & $189(11.24)$ & $1 / 116(0.86)$ & $1 / 73(1.37)$ & $\mathbf{9 7}(\mathbf{5 . 7 7})$ \\
TOTAL & $\mathbf{1 , 6 8 1 ( 1 0 0 )}$ & $\mathbf{6 0}(\mathbf{3 . 5 7})$ & $\mathbf{3 7}(\mathbf{2 . 2 0})$ & \\
\hline
\end{tabular}

$\chi^{2}=19.555, \mathrm{df}=10, \mathrm{P}=0.034<0.05$

Figure 2. Relationship between the population of Anopheles species dissected and their Microfilarial Incrimination Rates across four Localities in Makurdi

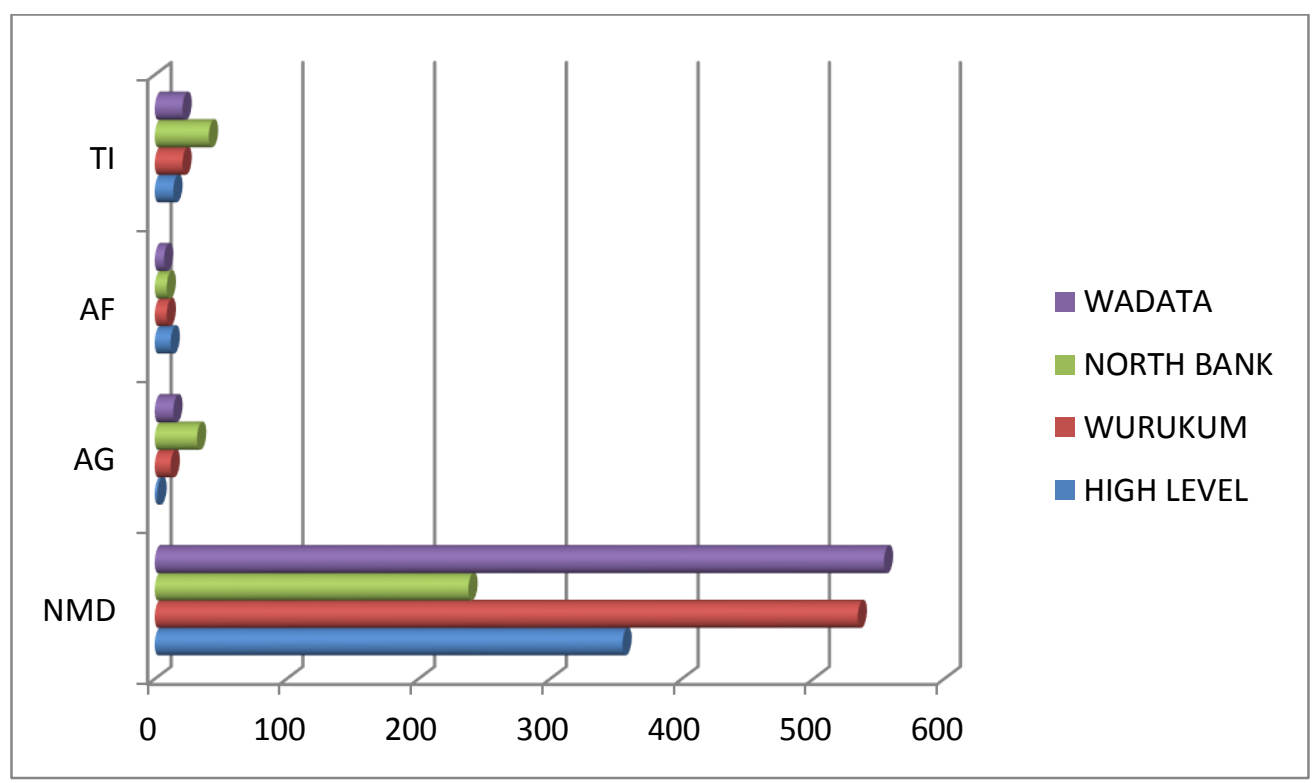

Key: $\mathrm{NMD}=$ Number of Mosquitoes Dissected; $\mathrm{AG}=$ Anopheles gambiae $; \mathrm{AF}=$ Anopheles funestus $; \mathrm{TI}=\mathrm{Total}$ Incrimination 
Table 3: Seasonal occurence of microfilarial incrimination rates of principal Anopheles vectors in Makurdi.

\begin{tabular}{|c|c|c|c|c|c|}
\hline Anopheles species/ seasons & $\begin{array}{l}\text { Number of } \\
\text { mosquitoes } \\
\text { Dissected }\end{array}$ & $\begin{array}{l}\text { No. with } \\
\mathrm{L}_{1}\end{array}$ & No. with $\mathrm{L}_{2}$ & No. with $\mathrm{L}_{3}$ & $\begin{array}{l}\text { Incrimination } \\
\text { Rate }(\%)\end{array}$ \\
\hline \multicolumn{6}{|l|}{$\begin{array}{l}\text { Wet Season 1: } \\
\text { (July-Oct. 2011) }\end{array}$} \\
\hline Anophelesgambiae s.l. & 545 & 1 & 3 & 6 & 1.83 \\
\hline Anopheles funestus & 362 & 0 & 1 & 5 & 1.66 \\
\hline Sub total & 907 & 1 & 4 & 11 & 3.49 \\
\hline \multicolumn{6}{|l|}{$\begin{array}{l}\text { Dry Season: } \\
\text { (Nov. 2011-March, 2012) }\end{array}$} \\
\hline Anopheles gambiae s.l. & 148 & 14 & 21 & 12 & 31.76 \\
\hline Anopheles funestus & 69 & 16 & 5 & 10 & 44.93 \\
\hline Sub total & 217 & 30 & 26 & 22 & 35.95 \\
\hline \multicolumn{6}{|l|}{$\begin{array}{l}\text { Wet Season 2: } \\
\text { (April-June, 2012) }\end{array}$} \\
\hline Anopheles gambiae s.l. & 347 & 0 & 0 & 3 & 0.86 \\
\hline Anopheles funestus & 210 & 0 & 0 & 0 & 0.00 \\
\hline Sub total & 557 & $\mathbf{0}$ & $\mathbf{0}$ & 3 & 0.54 \\
\hline Total & 1,681 & 31 & 30 & 36 & 5.77 \\
\hline
\end{tabular}

\section{Discussion}

This is the third time, after the report of Manyi and Imandeh (2008) that Anopheles gambiae and Anopheles funestus were featuring in the study area. The population of the two Anopheles species was found to be low. Among these mosquitoes, Anopheles gambiae sl had the highest population in the dry season across the four localities. This is in agreement with the findings of Nwoke (2010); FMOH (2009), who stated that Anopheles gambiae and Anopheles funestus are the main vectors in rural Nigeria while Culex quinquefasciatus remains the major vector in the urban and semi-urban areas. This is linked to the fact that the latter species is known to breed in poorly sanitized areas with filthy and fowl smelling water collections that are eminent in the study area (Manyi and Imandeh, 2008). This may explain why Targema et al. (2008) reported Wuchereria bancrofti infection to be a major public health problem in Benue State and advocated for the inclusion of the state in the National Programme to Eliminate Lymphatic Filariasis (NPELF). Also working in Ebonyi State, in Nigeria, Amaechi et al. (2011) reported Culex quinquefasciatus as the major vector with Anopheles gambiae and Anopheles funestus also playing significant roles in the transmission of lymphatic filariasis in the area.

The low microfilarial incrimination rate of $5.77 \%$ recorded in this study may be related to the fact that Anopheles species have been known to be minor vectors of the disease in urban and semi urban areas (Taylor, 1930) in Northern Nigeria. It is also in consonance with the findings of Kuhlow (1987) that Culex quinquefasciatus is the major vector of bancroftian filariasis in most West African cities. The overall microfilarial infection rate reported in the present study is therefore, comparable to reports from filariasis endemic countries (WHO, 1999; Pedersen and Mukolo, 2012) but is much higher than that of Awolola et al. (2006), who reported an overall microfilarial infection rate of $0.5 \%$ in the localities around Kainji Lake in Nigeria.

Concomitant infection of Plasmodium falciparum with Wuchereria bancrofti in human population has been reported in India (Ghosh and Yadav, 1995). Similarly, co-infection of Wuchereria bancrofti and Onchocerca volvulus has been reported in human populations in Tanzania (Makunde et al., 2003). On the contrary, co-infection of neither Plasmodium species nor Onchocerca volvulus and Wuchereria bancrofti was recorded in any Anopheles specimen. The reason for this may not be far from the behaviour of the vector species and duration of parasite cycles in the mosquito as also advanced by Service (2012). Moreover, several authors have reported that the life cycle patterns, behaviour and ecology of microfilariae have significant effects on their appearance in the thoracic muscles and or salivary glands of infected mosquitoes (Manguin et al., 2010; Service, 2012; Nwoke et al., 2010; Chandler and Read, 1969).

It has also been reported that multiple infections in mosquitoes do not promote parasite transmission (Manguin et al., 2010; Bryan, 1986). Consequently, the simultaneous transmission of Wuchereria bancrofti and Plasmodium falciparum is considered rare as it has been documented in Tanzania (Muirhead-Thomson, 1953). Similar studies along the Kenyan coast reported that only $0.06 \%$ and $0.4 \%$ of Anopheles gambiae complex were co-infected by the infective stages of Wuchereria bancrofti and 
Plasmodium falciparum (Kubasu, 1997; Muturi et al., 2006). Moreover, it has been generalised by Ravindran et al. (1998) that "although, potential vectors may be plentiful, the actual number of simultaneous infections in humans appear lower than expectations". In spite of the high number of Anopheles vectors dissected for incrimination rate of Wuchereria bancrofti in the study area, there was no single record of co-infection of the two parasites in the present investigation.

Microfilarial incrimination rates have been reported elsewhere in Nigeria: Anosike and Onwuliri (1992) reported a high experimental filarial incrimination rate of $74.6 \%$ in laboratory reared Culex quinquefasciatus in the Jos area (middle belt region); Inyama et al. (2003) reported an overall microfilarial infection rate of $5.5 \%$, also in the Jos area; Manyi and Imandeh (2008) reported a lower microfilarial incrimination rate of $2.26 \%$ in Makurdi- the present study area. Reasons for the differences in these results compared to the $5.77 \%$ incrimination rate obtained in the present study cannot be precisely itemised. However, the explanations may be similar to those provided by Uttah et al. (2013c) that vector species, sample size, fluctuations in environmental parameters and vulnerability of the human hosts in the respective study areas could affect the incrimination rates.

The result of the present investigation is at variance with the incrimination rates of Wuchereria bancrofti (9.2\% and $11.1 \%$ ) reported by Lenhart et al. (2007) in Anopheles gambiae s.s. and Anopheles arabiensis respectively in Central Nigeria.

The results of the present study show that the microfilarial incrimination rates were low during the wet season and relatively higher during the dry season in the study area. This means that the risk of transmission of Wuchereria bancrofti larvae by the two Anopheles vectors would be more during the dry season period in the Makurdi area than during the wet season. This is in disagreement with the findings of Kasili et al. (2009). The present report at Makurdi is also contrary to the findings of Brengues et al. (1968) who demarcated three discrete periods of Wuchereria bancrofti transmission in West Africa: firstly from May to July (early wet season), secondly from August to September (end of wet season) and thirdly from October to November (early dry season) as periods of low, intense and moderate transmissions respectively. The seasonal contrast between the result of this study compared to those of Kasili et al. (2009) and Brengues et al. (1968) may be linked to factors that control the movement of microfilariae in the vectors. Moreover, Chandler and Read (1969) reported that microfilariae prefer warm, moist skin in warm weather to be able to leave the mosquito's salivary glands to penetrate the host; cold weather makes them inactive while dryness destroys them. The higher occurence of $\mathrm{L}_{3}$ (infective larvae) in the mosquitoes in this study may therefore, be one explanation for their inability to leave the salivary glands during the dry season.

High ambient humidity and skin moisture have been reported to favour successful transmission of lymphatic filarial microfilariae, since the vector's salivary glands play no role in the transmission process (Manguin et al., 2010). This may also be one reason why there was higher microfilarial incrimination during the dry season than the wet season; biting activity and transmission were reduced during the dry season, making the vectors to harbour more microfilariae in their salivary glands than during the wet season in the study area.

Chandler and Read (1969) reported $\leq 80^{\circ} \mathrm{F}\left(26.9^{\circ} \mathrm{C}\right)$ and $90 \%$ humidity as optimum conditions for microfilarial growth. It thus implies that not all of the ingested microfilariae in the mosquitoes for this study would have developed to $L_{3}$ infective larvae. The high temperature usually experienced in the Makurdi area $\left(\leq 100^{\circ} \mathrm{F}\right)$ may also have contributed in reducing the activity of the microfilariae during mosquito bites, thus leaving them lodged in the salivary glands of the vectors.

One reason for the comparatively low microfilarial incrimination rate in the present investigation may be the initial control effort of December, 2004 and March, 2005 by the Global Programme to Eliminate Lymphatic Filariasis (GPEWLF) in Benue State where mass chemotherapy using ivermectin and Albendazole was done as part of efforts to eliminate the disease (Targema et al., 2008). This may also be the reason why Targema et al. (2008) mapped lymphatic filariasis in Benue State but did not record even a single infection out of the 100 human individuals examined for the disease. Furthermore, Chandler and Read (1969) reported that in order for an infective human host to infect mosquitoes, there must be about 15 or more microfilariae per drop of blood (20cu.mm).

They also reported that a high concentration of 100 or more microfilariae per drop of blood would rather kill the mosquitoes. This implies that if the recommended dosage is not met by the human host, the mosquitoes would not get infected.

\section{Conclusion}

The overall microfilarial incrimination rate in the Anopheles species was low compared to other studies that included Culex quinquefasciatus as a vector. The incrimination rates were significantly higher in Anopheles gambiae s.l. than in Anopheles funestus, 
while Wuchereria bancrofti was the only filarial nematode encountered during the study.

The results obtained in the present study have shown that the microfilarial incrimination rates were lower during the wet season than during the dry season in the study area. This implies that the potential risk of transmission of Wuchereria bancrofti larvae would be more in the dry season. Hence, dry season breeding sites and adult populations of Anopheles vectors in the study area should be controlled.

\section{Acknowledgements}

We acknowledge Emeritus Professor Vajime, Charles Gbilekaa for vetting this manuscript and Dr. Patience Onuche Agada of the department of Mathematics, Statistics and Computer Science, University of Agriculture, Makurdi-Nigeria for his help in the statistical analysis. We are also grateful to $\mathrm{Mr}$. Kumbur, Joseph for his technical assistance and provision of relevant materials that aided in the species identification and dissection of the mosquitoes.

\section{References}

1) Abeyasingha, R.R., Yapabanadara, A.M., Kusumawathie, P.H.D., Perera, D., Peiris, B.S. L., Hewavitharane, H.M.P. and Harshchandra, R.D.J. (2009). Guidelines for Entomological Surveillance of Malaria Vectors in Sri Lanka. Anti-Malaria Campaign, Pp 62-67.

2) Agi, P.I and Ebenezer, A. (2009). Observations on Filarial Infection in Amassoma Community in and Envir Manag, 13(1):15-19.

3) Aigbodion, F. I. and Nnoka, H. C. (2008). A Comparative study of the activities of Anopheles gambiae, Culex quinquefasciatus and Aedes aegypti (Diptera: Culicidae) by Pyrethrum Spray collection in Benin City, Nigeria. Biosc Res Comm, 20(3): 147-151.

4) Amaechi, A.A., Nwoke, B.E.B. and Ukaga, C.N. (2011). A Comparative Study of Human

Filarial Transmission Indices Control Trial Using Insecticide Treated Bed Net (ITBN) in Ebony State, Nigeria. Glob Res J Sci, 1:18-23.

5) Anosike, J.C. and Onwuliri, C.O.E. (1992). Experimental Wuchereia bancrofti infection of Culex quinquefasciatus and Aedes aegypti. Angew. Parasitol, 33: 139-142

6) Anosike, J.C., Nwoke, B.E., Ajayi, E.G., Onwuliri, C.O., Okoro, O.U., Asor, J.E., Amajuoyi, O.U., Ikpeama, C.A., Ogbusu, F.I and Meribe, C.O. (2005). Lymphatic filariasis among the Ezza people of Ebony State, Eastern Nigeria. Annals of Agricultural Environment and Medicine, 12(2):181-186.

7) Anosike, J.C., Onwuliri, C.O.E and Onwuliri, V.A. (2003). Human filariasis in Dass local government area of Bauchi State, Nigeria. Trop. Ecol., 44(2): 217-227.

8) Awolola, T.S., Idowu, E.T., Adeneye, A.K., Mafe, M.A., Oduola, A.O., Ogunrinade, A.F., Appelt, B. and Coetzee, M. (2006). Entomological Survey and Infection Rates of Plasmodium falciparum and Wuchereria bancrofti in Mosquito Populations in the Kainji Lake Area, Nigeria. Nigerian Journal of Parasitology, 27:58-61.

9) Badaki, J.A. (2010). Parasitological and Social Aspects of Lymphatic Filariasis in Taraba State. Ph.D Thesis in the Department of Zoology, University of Jos, Nigeria, 137 Pp.

10) Brengues, J., Subra, R., Mouchet, J. and Nelson, G.S. (1968).Transmission of Wuchereria bancrofti Cobbold in West Africa. Preliminary Study of a focus in the savannah of North Guinea. Bull W Hlth Org, 38: 595- 608.
11) Bryan, J.H. (1986). Vectors of Wuchereria bancrofti in the Sepik Provinces of Papua New Guinea. Trans $R$ Soc Trop Med and Hyg, 80: $123-131$.

12) Chandler, A.C and Read, C.P. (1969). Introduction to Parasitology. $10^{\text {th }}$ Ed. Library of Congress Catalog card number: 61-5670, USA, Pp473-494.

13) Coetzee, M. (2000). Distribution of the African Malaria Vectors of the Anopheles gambiae complex. A publication of the vector control reference unit, National Institute for communicable diseases, Johannesburg, south Africa, Pp. 1-2.

14) Coetzee, M., Craig, M, and le Sueur, D. (2000). Distribution of African Malaria Mosquitoes Belonging to the Anopheles gambiae Complex. Parasitol. Today, 16 (2): 74-77.

15) Dandalo, L. C. (2007). The Abundance and Biting Behaviour of Anopheles merus (Dontz) in Gokwe South District, Zimbabwe. A published M.Sc. Thesis in the Department of Biological Sciences, Faculty of Science, University of Zimbabwe, 48Pp.

16) Eigege, A., Richards, F.O., Blaney, I.D.D., Miri, E.S; Gontor, I., Ogah, G. et al (2003). Rapid Assessment for lymphatic filariasis in Central Nigeria: A comparism of the Immunochromatographic card test and hydrocoele rates in an area of high endemicity. Am J Trop Med and Hyg, 68(6):643646.

17) Federal Republic of Nigeria, Official Gazette. (2007). Legal Notice on Publication of the Details of the Breakdown of the National and State Provisional Totals, 2006 Census, 94: B175-B198.

18) FMOH (Federal Ministry of Health). (2009). National Malaria Control Programme Abuja, Nigeria. Strategic Plan 2009-2013: A Road Map for Malaria Control in Nigeria, 39Pp.

19) Ghosh, S.K., Yadav, R.S. (1995). Naturally acquired concomitant infections of bancroftian filariasis and human Plasmodia in Orissa. Ind J Malar, 32: 32- 36.

20) Gillies, M.T. and Coetzee, M. (1987). A supplement to the Anophelinae of Africa, South $\mathrm{Thf}$ theSghrgra Johanngsburg: South African Institute of Medical Research, 143Pp.

21) Goodman, D.S., Orelus, J.N., Roberts, J.M., Lammie, P.I., Streit, T.G. (2003). PCR and Mosquito dissection as tools to monitor filarial infection levels following mass treatment, Filar J, 2: Pp11.

22) Inyama, P.U; Anyanwu, G. I., Onyeka, J.O.A and Yusuf, I. (2003). Infestation Rates of Mosquitoes (Diptera: Culicidae) with malaria and Lymphatic filariplriparasites in aflateau State, Nigeria. J League Res in Nig, 4(2):89-96.

23) Kasili, S., Oyieke, F., Wamae, C and Mbogo, C. (2009) Seasonal Changes of Infectivity Rates of Bancroftian Filariasis Vectors in Coast Province, Kenya. J Vect B Dis, 46 219-224.

24) Kubasu, S.S. (1997). The Vectors of Malaria and Filariasis in Kilifi and Kwale Districts of Kenya. Kenyatta University, Nairobi. Pp 153.

25) Kuhlow, F. (1987). Observations and experiments on Culex antennatus Backer as a potential Vector of Bancroftian filariasis in West Africa. Ann Trop Med and Parasitol, 38: $349-350$.

26) Laumann, V. (2010). Environmental Strategies to replace DDT and control Malaria. $2^{\text {nd }}$ extended edition: Pestizid Aktions-Netzwerk (PAN) e.V, 40Pp.

27) Lenhart, A., Eigege, A., Kal, A., Pam, D., Miri, E. S., Gerlong, G., Oneyka, J., Sambo, Y., Danboyi, J., Ibrahim, B., Dahl, E. Kumbak, D., Dakul, A., Jinadu, M. Y., Umaru, J., Richards, F. O. and Lehmann, T. (2007). Contributions of different mosquito species to the transmission of lymphatic filariasis in central Nigeria: Implications for monitoring infection by PCR in mosquito pools. Filarial Journal, 6: 14 doi: 10.1186 / $1475-2883-6-14$ http://www.filariajounral.com/content/6/1/14

28) Makunde, W. H., Kamugisha, L. M., Massaga, J. J., Makunde, R. W., Savael, Z. X., Akida, J., Salum, F.M. and Taylor, M. J. (2003). Treatment of co-infection with bancroftian filariasis and onchocerciasis. A safety and 
efficacy study of albendazole with ivermectin compared to treatment of single infection with bancroftian filariasis. Filarial Journal, 2: $15-21$.

29) Manguin, S., Bangs, M. J., Pothikasikorn, J., and Chareonviriyaphap, T. (2010). Review on Global Cotransmission of Human Plasmodium species and Wuchereria bancrofti by Anopheles Mosquitoes. Infect, Gen. and Evol., 10: $159-177$.

30) Manyi, M.M and Imandeh, G.N. (2008). Infection Rates of Mosquitoes with Malaria and Lymphatic Filarial Parasites in Makurdi, Benue State-Nigeria. J Pest, Dis and Vect Manag, 8: $464-470$.

31) Muturi, E.J., Mbogo, C.M., Ng'ang'a, Z.W., Mwandawiro, C., Novak, R.J., Beier, J.C. (2006b). Relationship between malaria and filariasis transmission indices in an endemic area along the Kenyan Coast. Journal of Vector Borne Diseases 43: 77 -83.

32) Muirhead - Thomson, M.C. (1953). Inter-relationships between filarial and malarial infections in Anopheles gambiae. Nat, 172: 352 - 353 .

33) Nwoke, B. E. B., Nwoke, E. A., Ukaga, C. N. and Nwachukwu N. I. (2010). Epidemiological Characteristics of Bancroftian filariasis and the Nigerian environment. $J P u b$ Hlth and Epi, 2(6): 113-117.

34) Nyagba, J. L. (1995). The geography of Benue State. In: A Benue Compendium. Denga, D. I. (Ed) Calabar, Rapid Educational Publishers Ltd, Pp 85 - 97.

35) Oguoma, V.M., Nwaorgu, O.C., Mbanefo, E.C., Ikpeze, O.O., Umeh, J.M., Eneanya, C.I. and Ekwunife, C.A. (2010). Species Composition of Anopheles mosquitoes in three villages of Uratta Owerri north Local Government Area of Imo State, Nigeria. Reviews in Infection, 1(4): 192-196.

36) Okon, O.E., Iboh, C.I and Opara, K.N. (2010). Bancroftian Filariasis among the Mbembe people of Cross River State, Nigeria. J. Vect B Dis., 47(2):91-96.

37) Omudu, E. A. and Ochoga, J. O. (2011). Clinical epidemiology of lymphatic filariasis and community practices and perceptions amongst the Ado people of Benue State, Nigeria. Afr J Infect Dis, 5(2):4-53.

38) Service, M.W. (2012). Medical Entomology for Students. $5^{\text {th }}$ edn, Cambridge University Press, New York, 303Pp.

39) Pedersen, E. M. and Mukolo, D. A. (2012). Impact of insecticide-treated materials on filarial transmission by the various species of vector mosquito in Africa. Ann Trop Med and Parasitol, 96: 91 - 95.

40) Ravindran, B., Sahoo, P.K., Dash, A.P. (1998). Lymphatic filariasis and malaria: concomitant parasitism in Orissa, India. Trans R Soc Trop Med and Hyg, 92: $21-23$.

41) Targema, C.N., Onwuliri, C. O. E., Mafuyai, H.B., Mwansat, G.S., Aida, A., Eigege A., Ityonzughul, C., Kal, A., Orkurga, A. and Jinadu, M.Y. (2008). Mapping of lymphatic filariasis in Benue State, Nigeria. Nigerian Journal of Parasitology, 29 (1): $55-61$.

42) Taylor, A.W. (1930). The Domestic Mosquitoes of Gadau, Northern Nigeria, and their relationto malaria and filariasis. Ann Trop Med and Parasitol, 24: 425 - 435.

43) Udo, K. R. (1981). Geographical Regions of Nigeria. London, Morrison and Gibb Ltd, Pp 133 - 149.

44) Udoidung, N.I., Braide, E.I.,Okpara, K.N., Ating, I.A and Adie, H.A. (2008). Current statusof bancroftian filariasis in rural communities of the lower Cross River basin, Nigeria: Parasitological and Clinical aspects. J. Pub. Hlth, 16:383388.

45) Udonsi, J.K. (1988). Bancroftian filariasis in the Igwu Basin, Nigeria. An epidemiological, Parasitological and clinical study in relation to the transmission dynamics Act Trop, 45:171-179.

46) Ungureanu, E.M. (1972). Methods for Dissecting Dry Insects and Insects Preserved in FixativeSolutions or by Refrigeration. Bull World Hlth Org, 47: 239-244.

47) Uttah, E. C., Iboh, C. I., Ajang, R., Osim, S.E. and Etta, H. (2013c). Physiological age composition of female Anopheline mosquitoes in an area endemic for malaria and filariasis. Int J Sci and Res Publ, 3(7): ISSN 2250 - 3153.

48) World Health Organisation. (2010). The Regional Strategic plan for Elimination of Lymphatic filariasis, (2010-2015), $21 \mathrm{Pp}$.

49) World Health Organization. (2002). Malaria Entomology and Vector Control. Learner's guide. WHO, Geneva, 126Pp.

50) World Health Organization. (1999). Expert Committee on Vector Biology and Control. Geneva $6^{\text {th }}-10^{\text {th }}$ December 1999.

51) World Health Organization (1975). Manual on Practical entomology in Malaria. Part I and II.

52) Methods and Techniques. World Health Organization Offset Publication, Geneva, Switzerland, 13, 1 Pp 160 